\title{
Políticas públicas, processos de planejamento e constituição dos sistemas educacionais em Brasil e Argentina: um estudo comparativo
}

\author{
Public policies, planning processes and educational systems constitution in \\ Brazil and Argentina: a comparative study
}

Políticas públicas, procesos de planeamiento y constitución de los sistemas educativos en Brasil y Argentina: un estudio comparativo

\section{SILVINA JULIA FERNÁNDEZ \\ IVANA DARIELA BRIGNARDELLO \\ ANDREA ELISABET HERNAN \\ BÁRBARA ISABEL CORREA \\ GABRIELA ANDRETICH}

\begin{abstract}
Resumo: $O$ artigo aborda os processos de planejamento educacional na constituição dos sistemas educacionais na Argentina e no Brasil através de um estudo comparativo com foco na formulação de políticas educacionais e seus modos de planejamento. Sob perspectiva qualitativa, a partir da bibliografia específica e da legislação que regula a política educacional em cada país, identificamos as características históricas e contextuais que colaboraram na definição de estilos de planejamento educacionais específicos desde os momentos de início de configuração institucional dos sistemas educacionais até 2016.
\end{abstract}

Palavras-chave: pesquisa comparada, planejamento educacional, política educacional, sistemas educacionais.

Abstract: The article discusses the educational planning processes in the educational systems constitution in Argentina and Brazil through a comparative study focused on the formulation of educational policies and their modes of planning. In a qualitative perspective, based on the specific bibliography and the legislation that regulates the educational policy in each country, we identify the historical and contextual characteristics that collaborated in the definition of specific educational planning styles from the beginning of the institutional configuration of the educational systems until 2016.

Keywords: comparative research, educational planning, educational policy, educational systems. 
Resumen: El artículo aborda los procesos de planeamiento educativo en la constitución de los sistemas educativos en Argentina y Brasil a través de un estudio comparativo con foco en la formulación de políticas educativas y sus modos de planeamiento. Con perspectiva cualitativa, a partir de la bibliografía específica y de la legislación que regula la política educativa en cada país, identificamos las características históricas y contextuales que colaboraron con la definición de estilos de planeamiento educativo específicos desde los inicios de configuración institucional de estos sistemas hasta 2016.

Palabras clave: investigación comparada, planeamiento educativo, política educativa, sistemas educativos.

\section{INTRODUÇÃO}

Este artigo vincula-se ao projeto de pesquisa "Políticas educacionais comparadas Brasil e Argentina. Primeira etapa: os processos de planejamento em nivel nacional posteriores à década de 1990", realizado em conjunto entre a Universidade Federal do Rio de Janeiro (Brasil) e a Universidade Nacional de Entre Rios (Argentina). A pesquisa procura produzir conhecimento comparado acerca dos processos políticos no Brasil e na Argentina entre 2003 e 2016 relacionados ao planejamento educacional nacional.

Aqui, especificamente, apresentamos uma recapitulação de processos histórico-políticos de ambos os países com base em categorias que nos permitem descrever os processos de formulação das políticas educacionais - como centralização/descentralização, papel do Estado, influência ou incidência de organismos de planejamento -. Essas categorias colaboram com a análise de processos de planejamento relacionadas ao momento de produção de políticas visando ao reconhecimento de estilos de planejamento em ambos os contextos nacionais. As fontes utilizadas são principalmente secundárias, como normativas e outros documentos oficiais.

Cabe destacar, aliás, a importância de um estudo comparado para estudar o planejamento educacional. Na América Latina, os estudos comparados em Educação têm desenvolvimento relativamente recente. Na década de 1990, fortaleceram-se em torno da reconfiguração das relações internacionais e a influência das agências internacionais de financiamento, com temas de política educacional e gestão escolar (ZEMELMAN, 2003; KRAWCZYK, 2013). 
É assim que, a partir dos anos 90 do século XX, vamos observar que a pesquisa comparada em educação toma um novo fôlego na América Latina. Os organismos internacionais foram importantes indutores não somente das reformas educacionais ocorridas durante esse período na região, mas também na produção de conhecimento como dispositivo regulador e de governança (NÓVOA, 1995 apud.KRAWCZYK, 2013, p. 202)

Nesse contexto, na tentativa sistemática de uniformizar as políticas nacionais através de condicionantes supranacionais, a comparação tem um grande potencial de interpretação. Nohlen (2006) afirma que o pesquisador deve decidir sobre diferentes aspectos para lograr uma relação metodologicamente razoável que permita observar mais de perto algumas variáveis na seleção de casos, como o âmbito do objeto de estudo, o contexto, o tempo e o espaço. Isto supõe que a comparação entre políticas educacionais requer variáveis articuladas com uma série de relações culturais, ideológicas e axiológicas (nem sempre quantificáveis) que configuram os processos socias.

\section{POLÍTICA E PLANEJAMENTO EDUCACIONAL NA CONFIGURAÇÃO DOS SISTEMAS EDUCACIONAIS ARGENTINO E BRASILEIRO: CONTEXTUALIZAÇÃO HISTÓRICA}

As Constituições são as ferramentas jurídicas básicas dos Estados modernos, onde se plasmam os direitos dos cidadãos e a forma de governo que adquirem. No caso argentino, a primeira Constituição Nacional foi sancionada em 1853, estabelecendo aspectos associados à educação como direito que serão relevantes para analisar o processo de conformação e expansão do sistema educacional.

Artículo 5.- Cada provincia confederada dictará para sí una Constitución bajo el sistema representativo republicano, de acuerdo con los principios, declaraciones y garantías de la Constitución Nacional; y que asegure su administración de justicia, su régimen municipal, y la educación primaria gratuita.

Artículo 14.- Todos los habitantes de la Nación gozan de los siguientes derechos conforme a las leyes que reglamenten su ejercicio; a saber: de trabajar y ejercer toda industria lícita; de navegar y comerciar; de peticionar a las autoridades; de entrar, permanecer, transitar y salir del territorio argentino; de publicar sus ideas por la prensa sin censura previa; de usar y disponer de su propiedad; de asociarse con fines útiles; de profesar libremente su culto; de enseñar y aprender. 
Atribuciones del Congreso. Artículo 64.- Corresponde al Congreso:

Inciso 16. Proveer lo conducente a la prosperidad del país, al adelanto y bienestar de todas las provincias, y al progreso de la ilustración, dictando planes de instrucción general y universitaria (Constitución de la Confederación Argentina, 1853)

Estes artigos permitem compreender como se organizou o governo da educação em relação a responsabilidades e atribuições do estado nacional e das províncias. $\mathrm{Na}$ Argentina, esse pacto constitucional se viu consolidado através de diversas ações e normativas, como a implantação do Ministério de Justiça, Culto e Instrução Pública, em 1854; o primeiro censo da educação nacional, em 1863; a Lei de Subvenções Escolares, que propiciava ajuda financeira às províncias para a oferta educacional, em 1871, e a destinação de fundos nacionais para a construção de prédios escolares; a criação do Conselho Nacional de Educação, em 1881, entre outras (PUIGGRÓS, 2006).

Essa estruturação institucional demonstra que

El proceso de invención de la Argentina y de los argentinos con el que nuestro país ingresa en el siglo XX, tiene uno de sus pactos fundantes en la educación. En la institución de esa nueva sociedad, el edificio educativo cumplía un papel central que se extendió a lo largo de las primeras décadas de este siglo, con el que lo escrito, el universo de lo letrado, se transforma hasta alcanzar la centralidad de la cultura, ese núcleo donde se le da sentido a las cosas y a los hombres. La decidida intervención del Estado en este ambicioso proyecto educativo no sólo fue capaz de dar un sentido colectivo a una sociedad de mezcla, sino que a la postre se reveló como la impronta más duradera y distintiva del país (MACOR, 2000, p. 347).

Ainda entre 1900 e 1950 o sistema educacional primário teve um desenvolvimento de matrícula importante e, conforme aponta Southwell (2006), a estrutura institucional da educação pública se consolida nas capitais das províncias, irradiando para o interior, ostentando grande capacidade de abrangência, regulação e administração do sistema em todo o território nacional. Para fins desse período, a matrícula escolar pode se considerar massiva, junto com o desenvolvimento da burocracia destinada à sua administração.

Enquanto isso, no Brasil, a configuração do sistema educacional apresentou outros processos. Nesse sentido, a descentralização acompanhou a própria definição da federação brasileira, pois, como aponta Fávero (1999, p. 107), 
Após o Ato Adicional de 1834, referendado pela Constituição de 1891, assim como pela Revisão de 1926, estabeleceu-se um federalismo educacional, pelo qual o ensino das primeiras letras ficou a cargo primeiro das Províncias, depois dos Estados recém-criados. Na verdade, durante todo o Império e a Primeira República, essa "descentralização" significou verdadeiramente a omissão da União em relação à educação popular, tal como era entendida na época, ou seja, extensão do ensino elementar às camadas populares.

As províncias, por falta de interesse ou de recursos, não se ocuparam desta oferta educacional ficando totalmente relegada (BITTAR et al., 2012). No início do século XX, o Brasil mantinha ainda uma sociedade rural, com uma pesada herança escravista, uma educação elitista e baixa demanda escolar.

Constatamos que a estruturação do ensino público no Brasil começa a se efetivar após os anos de 1930, quando nos diversos momentos do governo de Getúlio Vargas começa a se entender a educação como uma questão nacional, justificando a criação do Ministério de Educação e Saúde Pública, em 1930, e afirmando-se essa ideia na Constituição de 1934, com a inclusão de alguns princípios básicos relativos ao papel diretor da União, instituindo os conselhos de educação, a vinculação de recursos orçamentários para a educação, entre outros (FÁVERO, 1999). Conforme o dispositivo legal, também se torna competência da União a elaboração de um plano nacional de educação, sob a responsabilidade do Conselho Nacional de Educação (SAVIANI, 2007).

Os parágrafos precedentes demonstram que a estruturação do campo educacional foi diferencial em ambos os países, com uma expansão e organização nacional antecipada na Argentina e tardia no Brasil.

As tensões entre centralização e descentralização nos processos de tomada de decisões e a construção de políticas educacionais são analisadas por Plomé (2002), que coloca as seguintes preguntas: Quem toma a decisão sobre a ordenação básica da educação? Quem estabelece as condiciones para obter os títulos académicos? Quem expede o diploma? Quem toma a decisão sobre o currículo, quer dizer, sobre o conjunto de conteúdos, métodos e critérios de avaliação de cada um dos níveis educacionais que compõem o sistema? Quem controla ou supervisiona o sistema educacional? Quem financia o sistema educacional? Desta forma, quando a contestação a todas estas preguntas remete à organização central do Estado, estamos frente a um sistema estritamente centralizado. Pelo contrário, quando algumas ou todas as respostas remetem a outras instâncias, que não sejam o Estado Nacional, estamos frente a sistemas centralizados com tendências descentralizadoras ou frente a sistemas descentralizados em maior ou menor grau. 
Assim, na Argentina, a Constituição do sistema escolar e a conformação de um corpo estatal para a sua administração se definiram como estratégias de gestão e administração centralizada há 150 anos. Sua concepção associava-se com a modernidade, com a primeira etapa das revoluções industriais e com a construção das democracias republicanas como forma de governo dos estados nacionais. A configuração como aparato burocrático com as principais características que o constituem - e que ainda em parte se mantém - como sistema de instrução pública, com hegemonia estatal e subsidiariedade do setor educacional privado, com una estrutura fortemente centralizada e com relações verticais, foi um processo que se estendeu durante pelo menos três décadas. Neste modelo, a escola ficou significada como lugar de aplicação e execução linear da política educativa, que será continuada durante a etapa 1946 - 1955, durante os primeiros governos peronistas com a implementação de um projeto nacionalista, popular e industrializador, considerando à educação como una ferramenta fundamental para disseminar o ideário peronista. Essa lógica de estruturação do sistema, desde os primeiros momentos, penetrou na sociedade civil, ajudando à consolidação definitiva do Estado, à construção da ideia de nação e à incorporação das relações sociais de produção capitalista.

No Brasil, em meio a permanentes tensões políticas que incluem a gestão do ministro Gustavo Capanema (1934-1945) e a sua "ferrenha centralização político-administrativa" (FÁVERO, 1999, p. 108), incluindo a criação do Fundo para o Ensino Primário, em 1932, entre os anos de 1930 e 1964 constatamos diversas reformas educacionais que, contudo, não conseguiram resolver o problema histórico de analfabetismo nem a garantia de quatro anos de escolaridade obrigatória. Assim,

Em síntese, desde a constituição do Estado Nacional, que se fez a partir dos anos 30 com a primazia do Poder Executivo sobre os outros poderes, introduziuse explicitamente a definição das políticas educacionais pelo arsenal das leis de reforma do ensino, às quais se acoplou o mecanismo de distribuição e controle do uso das verbas orçamentárias vinculadas para a expansão do ensino primário, depois do $1^{\circ}$ grau, hoje ensino fundamental. Mesmo após a Constituição liberal de 1946, que definiu constitucionalmente a vinculação de verbas para a educação e que introduziu a obrigação da Lei de Diretrizes e Bases da Educação Nacional e do Plano Nacional de Educação, a União não abriu mão do seu poder centralizador. (FÁVERO, 1999. p. 107-108)

Posteriormente, com enormes variabilidades e condicionamentos históricos que refletem um padrão de modernização forçada das sociedades nacionais com o eixo diretor do estado, o desenvolvimentismo - com Arturo Frondizi, na Argentina, e Juscelino Kubitschek, no Brasil -, mantém-se muitas 
das vezes mascarado aproximadamente até a crise da década de 1980. Também se mantém, depois da década de 1960, uma taxa de 40\% de analfabetismo no Brasil, o que evidencia a ineficiência da normativa da época (BITTAR, et al. 2012), enquanto na Argentina essa taxa, já em 1938, apresentava apenas 12\% de população não alfabetizada.

Com efeito, apesar do Plano Nacional de Desenvolvimento, que prometia avançar "50 anos em 5", e de a Lei de Diretrizes e Bases da Educação Nacional (LDBEN) de 1961 ser considerada marco instaurador do planejamento educacional brasileiro através da exigência, entre outros, da elaboração de Planos Estaduais de Educação - conforme manual exigido pelo MEC - para utilização dos recursos vinculados, os governos não conseguiram concretizar esse esforço (FÁVERO, 1999). Aliás, cabe mencionar a criação do Ministério do Planejamento, em 1964, que em grande medida acabou conduzindo o sistema educacional em detrimento do próprio Conselho Nacional de Educação (HORTA, 1997).

Por outro lado, na Argentina, conforme relata Canelo (2012, p. 173):

[...] durante el gobierno de Arturo Frondizi (1958-1962) que se inició la “época dorada" de la planificación en la Argentina. Mediante la creación del Consejo Nacional de Desarrollo (CONADE), organismo responsable de "la coordinación y ejecución de los estudios y análisis requeridos para la formulación orgánica de los programas de desarrollo nacional" (Decreto No 7290, Boletín Oficial de la República Argentina, 30/8/1961, p. 4.), la Comisión de Administración del Fondo de Apoyo al Desarrollo Económico, y el Consejo Federal de Inversiones, la planificación alcanzó una inédita envergadura institucional. La misma fue seguida por una multiplicación de planes de desarrollo, como el Plan Nacional de Desarrollo 1965-1969 elaborado durante el gobierno de Arturo Illia, el Plan Nacional de Desarrollo y Seguridad 1971-1975 de la Revolución Argentina, y el Plan Trienal para la Reconstrucción y Liberación Nacional 1974-1977 durante el tercer gobierno peronista (MÜLLER, 2011; TERESCHUK, 2007).

A noção de educação para a formação de capital humano neste modelo foi decisiva para a busca de expansão dos sistemas de escolarização a partir dos conceitos mais tecnocráticos do modelo. Idêntica perspectiva, porém, aggiornada ${ }^{1}$, voltou a apresentar-se na década de 90, dando passo aos modelos de estabilização, ajuste estrutural e ao Estado neoliberal na região (TORRES, 2001). A antessala deste aggiornamento veio com a Revolução Conservadora nas últimas décadas do século XX - com R. Reagan, nos Estados Unidos, e M. Tatcher, na Inglaterra -, quando o liberalismo adquiriu o seu perfil mais selvagem, tornando-se cada vez mais ostensivo o individualismo das relações sociais e a influência de grupos de poder econômico nas decisões políticas. 
As ditaduras militares na América Latina foram o principal vetor que possibilitou a instauração do modelo neoliberal, aprofundado na década de 90. No plano da educação e da cultura, a hegemonia conformou um aparato ideológico que abrangeu o ensino em todos os níveis, a compra/aluguel/ proscrição de partidos políticos e dos meios de comunicação que buscaram ocultar, dissimular ou distorcer a resistência ativa dos sectores populares. O discurso do desenvolvimento aliou-se ao da segurança nacional, em especial, com referência ao controle ideológico e ao combate à denominada "subversão".

Esta confluencia entre planificación, seguridad y desarrollo alentó exitosas experiencias de crecimiento en varios países latinoamericanos. En Brasil, tras el golpe militar de 1964 liderado por el general Humberto de Alencar Castello Branco contra el presidente João Goulart, se ponía en marcha la experiencia pionera del Ministerio de Planejamento e Coordenação Economica, considerado pilar del "milagro económico" brasilero. En la Argentina, donde se iniciaba la década de mayor crecimiento económico de la segunda mitad del siglo XX (19641974), el régimen militar de la Revolución Argentina (1966-1973), observando atentamente la experiencia brasilera, puso en marcha un novedoso sistema de planificación. Durante la presidencia del general Juan Carlos Onganía (19661969), se estableció un complejo "Sistema Nacional de Planeamiento y Acción para la Seguridad Nacional”, que integraba tres subsistemas. (CANELO, 2012, p. 174)

No final do período das ditaduras militares, entretanto, o saldo não parecia tão alentador. Na Argentina, a conflitiva experiência do Ministério de Planejamento e do Projeto Nacional, expressão dos militares mais "duros" na coalisão nacional, estendeu-se apenas até o ano de 1977 (CANELO, 2012). No Brasil, criticava-se a grandiosidade das propostas em contraposição aos modestos resultados obtidos. Segundo Garcia (2003, 41-42), "A incapacidade de conciliar as proposições dos planos elaborados com a realidade vai transformando, progressivamente, o modelo de Planejamento Educacional em justificativa para toda sorte de casuísmos que invade a Educação a partir de 60 e 70". Da mesma forma, o autor apresenta uma caracterização do período, que pode ser sintetizada nos seguintes aspectos: duplicação de projetos e estruturas com pouca articulação entre si, pouca influência do Ministério da Educação e praticamente nula participação dos educadores na tomada de decisões fundamentais na formulação da política educacional, descontinuidade das ações, redução de planejamento a orçamento e diminuição da capacidade do Ministério de Educação de influir nos destinos da Educação. 
O panorama, evidentemente, não se apresentava favorável nem para os interesses hegemônicos dos setores neoliberais nem para as demandas populacionais. Tornava-se imperativa uma mudança na formulação e implementação das políticas educacionais, assim como da organização do próprio Estado.

Pouco a pouco, os regimes autoritários deram lugar a governos democráticos que ainda lutam por permanecer na região. A partir de 1982, com o fim da ditadura militar boliviana, começava uma época de retrocesso dos governos militares e de avanço e recuperação da democracia em vários países latinoamericanos como Argentina, Brasil, Uruguai, Chile e Paraguai. Perante o horror de ditaduras brutais, praticantes do terrorismo de Estado, a democracia política foi percebida como uma via mais eficaz para a solução de diversos problemas gerados durante e pelas ditaduras institucionais das forças armadas (ANSALDI, 2006).

\footnotetext{
La dictadura militar se encontraba en un proceso de deslegitimación política y al tiempo que crecía la conflictividad social tanto en el campo como en las ciudades con el avance de un renovado movimiento sindical, los distintos sectores sociales movilizados se articulaban en la aspiración de una democratización del país, que a su vez potenciaba las reivindicaciones sociales (...) Por último, puede señalarse la crisis de las "formas tradicionales de representación del mundo del trabajo y la emergencia de una nueva configuración de las clases populares. (MENDES PEREIRA, 2006, p.11)
}

Essa crise provocou o surgimento de novas identidades sociais e políticas que permitiram a conformação de novas organizações se comparadas aos tradicionais sindicatos construídos dentro da lógica da representação e os canais formais e legais da motivação social (GIARRACA, 2006).

$\mathrm{Na}$ Argentina, o governo democrático do período 1983-1989, com o Presidente Raúl Alfonsín, viu-se encurralado pelos grupos econômicos que deixaram o poder político, mas continuaram dominando a economia e provocando graves processos inflacionários. Esse contexto evidencia uma etapa de mobilização no terreno educacional, com significativas tentativas democratizadoras no primeiro momento. A preocupação pela democratização interna e externa do sistema educacional, expressa a partir de dezembro de 1983, é procurada através de diferentes medidas pelo governo da Unión Cívica Radical e esteve presente no discurso e em diversas políticas adotadas até 1988/89: a Campanha Nacional de Alfabetização, o livre ingresso a todos os níveis do sistema educacional, a liberdade de cátedra universitária e de agremiação de docentes e estudantes expulsos pela 
ditadura, a convocatória ao Congresso Pedagógico Nacional, a normalização das Universidades Nacionais com a realização de concursos públicos, entre outros (VIOR, 1999).

No Brasil, em 1984, inicia-se uma transição pactuada, conservadora, com o empurre da sociedade civil (ANSALDI, 2006). O governo de José Sarney foi conhecido pela sua hábil condução do processo de abertura democrática do país, culminando com a aprovação da Constituição Federal (CF) de 1988, denominada a "Constituição Cidadã", pela afirmação de uma democracia participativa através de diversos dispositivos institucionais e organizacionais para a elaboração e implementação de políticas públicas. $\mathrm{Na}$ educação, fruto das expectativas e pressões da sociedade civil organizada nos anos de 1980 e durante o processo constituinte pela democratização da sociedade e da educação pública (GÓMEZ; PINI MELO, 2011), começa a afirmar-se a gestão democrática das escolas públicas na CF de 1988, retomada pela Lei de Diretrizes e Bases da Educação Nacional de 1996 e reafirmada nos Planos Nacionais de Educação (PNEs) 2001-2010 e 2014-2024. A partir desse período, portanto, a educação brasileira - a diferença da argentina - está intimamente ligada à participação em educação dos cidadãos a partir da sua ingerência na informação, na prestação de contas, no planejamento e em possíveis reivindicações.

Essa etapa, conhecida como a primavera democrática na Argentina, apesar de manter institucionalmente o regime político constitucional, deu uma virada neoliberal com os governos de Fernando Henrique Cardoso, no Brasil, e de Carlos Menem, na Argentina, ambos marcados por vertiginosos processos de privatização, descentralização, desconcentração e desregulação do Estado (OZLACK, 1997).

No que diz respeito à descentralização, no Brasil, destacamos a Emenda Constitucional $\mathrm{N}^{\circ} 14$, de 1996, que modifica a CF de 1988. A partir desta normativa os municípios deverão passar a atuar prioritariamente na Educação Infantil e no Ensino Fundamental, assim como os Estados no Ensino Médio, enquanto a União fica incumbida da função redistributiva e supletiva, de forma a garantir equalização de oportunidades educacionais e padrão mínimo de qualidade do ensino mediante assistência técnica e financeira aos outros entes federativos. Também se criou o Fundo de Desenvolvimento do Ensino Fundamental e Valorização do Magistério (FUNDEF). Essas determinações configuraram um importante meio de descentralização da educação brasileira através da redistribuição de competências e verbas aos estados e municípios (OLIVEIRA, 2005). Os municípios ganharam em autonomia para organizar seus próprios sistemas de ensino e substanciou-se uma redistribuição das obrigações e responsabilidades no cumprimento de um dever legal do Estado para com seus cidadãos, pois, "O 
regime de colaboração entre as diferentes esferas administrativas foi considerado como meio indispensável à constituição de fato de um sistema único que possa focalizar o atendimento aos mais necessitados, funcionando de maneira integrada e articulada." (OLIVEIRA, 2005, p.12).

Nos anos de 1990, tanto na Argentina quanto no Brasil, a educação foi um dos muitos setores afetados pelo ajuste estrutural combinado com políticas neoliberais. As reformas educacionais daquele momento deram-se durante o processo de ajuste e desmantelamento do velho aparato estatal, onde a fé nas bondades curativas do mercado conspirou contra a racionalização das estruturas burocráticas necessárias para o desempenho de tarefas irrenunciáveis. Os ajustes de pessoal, funções e processos estiveram pautados pelas restrições orçamentárias. A descentralização tomou conta de diferentes áreas de governo, mudando o sentido que outrora se deu à descentralização como facilitador da participação local, que sofreram - como as escolas - sob uma pronunciação antiestatista e uma recentralização de decisões chave.

$\mathrm{Na}$ Argentina, a regulação política foi uma característica distintiva do acionar estatal nos anos 1990, limitando a soberania das jurisdições na tomada de decisões (FELDFEBER; GLUZ, 2011). Com o disfarce da distribuição do poder e na linguagem neoliberal de aproximar o usuário da educação à tomada de decisões se avançou com políticas de descentralização que tiveram o claro objetivo de desresponsabilizar o Estado Nacional do financiamento educacional para contar com maiores recursos para pagar a dívida externa. Houve, paralelamente, uma centralização de poder em relação a elementos de controle como os Pactos Federais Educacionais, vinculados ao repasses de verbas aos governos provinciais e destes aos municípios, e os Operativos Nacionais de Medição da Qualidade, com a implementação do Sistema Nacional de Avaliação da Qualidade.

No Brasil, os avanços em matéria de descentralização (administrativa, econômica e pedagógica) dos anos de 1980, deram marcha ré ao serem cooptados pela lógica neoliberal. O processo de democratização foi reinterpretado pelo Estado como a necessidade de imprimir una maior racionalidade a sua realização através de um conjunto de proposições que convergiram para outros modelos de gestão do ensino público fundamentados em formas mais flexíveis, participativas e descentralizadas de administração dos recursos e das responsabilidades. Deste modo, as reformas educativas dos anos de 1990 abrangeram um conjunto de orientações administrativas cujo marco referencial teórico e conceitual esteve eminentemente baseado em lógicas próprias da economia privada (STUBRIN, 2007). No âmbito da gestão da educação pública, os modelos fundamentados na flexibilidade organizacional traduziram-se na desregulação dos serviços educacionais e na descentralização dos recursos. Aparentemente, a escola era fortalecida como 
núcleo do sistema, porém, acabou promovendo uma qualidade educacional reduzida a termos mensuráveis que se alcançariam, supostamente, através de inovações organizacionais e na gestão escolar.

Após essa etapa, na Argentina, as análises se dividem em dois períodos: o primeiro, durante a presidência de Néstor Kirchner (2003-2007), caracterizada por transformações importantes na legislação com poucos avanços em função de políticas concretas que garantissem a sua efetivação; o segundo, inclui as decisões dos dois governos de Cristina Fernández de Kirchner (2007-2011, 2011-2015), nos quais se observam alguns avanços nas políticas destinadas à inclusão social.

No Brasil, durante os governos do Partido dos Trabalhadores (PT) que vão desde 2003 até 2016, destacam-se algumas medidas importantes também nesse sentido, como a ampliação da obrigatoriedade escolar básica após a Emenda Constitucional $\mathrm{n}^{\circ} 59$ e do acesso ao sistema universitário através de diversas formas (política de cotas, REUNI, PROUNI etc.), assim como a ampliação da cobertura do FUNDEF para o FUNDEB, abarcando assim também a Educação Infantil e o Ensino Médio, e a implementação de programas de assistência técnica e financeira através do Fundo Nacional de Desenvolvimento da Educação (FNDE), que chegara aos entes federativos a partir da implementação dos seus Planos de Ações Articuladas. Cabe também destacar as negociações na aprovação do Plano Nacional de Educação 2014-2024, que denotara as dificuldades de consenso nesse sentido, deixando o país sem plano do estado por quatro anos. Nesse ínterim, entretanto, continuava a se desenvolver o Plano de Desenvolvimento da Educação que, entre outras medidas importantes, implementava o Índice de Desenvolvimento da Educação Básica (IDEB) como medida de qualidade para escolas e entes federativos, combinando indicadores de fluxo e de proficiência dos estudantes em Matemática e Português, bianualmente, na Prova Brasil.

Pode-se afirmar que, nos casos de Argentina e Brasil neste último período, estamos frente a estados que recompuseram a sua capacidade regulatória e de investimento em educação. Segundo Pini e Gómez Melo (2011), as políticas recentes desenvolvidas em ambos os países tentaram revalorizar o lugar do Estado como regulador e administrador. Em educação, isto torna-se visível, por exemplo, no Brasil, pelas medidas que mostram a busca de centralidade na definição de políticas educacionais pelo Ministério de Educação. Na Argentina, verificam-se as tentativas de adoção de uma política que minimize a segmentação e a disparidade entre e dentro das províncias. Em geral, e no campo educacional em particular, a gestão de governo de Néstor Kirchner iniciou-se em um clima de rejeição às reformas dos anos de 1990 e seus efeitos. Na área educacional, anunciaram-se mudanças normativas vinculadas às demandas por desandar a Reforma Educacional da década anterior, implementada a partir da Lei Federal 
de Educação de 1993, que foi derrogada e substituída pela Lei de Educação Nacional no 26.206, em 2006, e sancionaram-se leis que constituíam motivo de lutas e reclamações, como as Leis de Educação Técnico-Profissional (26.058), de Financiamento Educacional (26.075) e de Educação Sexual Integral (26.150). A posição antagônica com relação à Lei Federal pode analisar-se no restabelecimento do Estado como responsável primário e garantia ineludível do cumprimento do direito à educação e da não mercantilização da educação.

\section{CONSIDERAÇÕES FINAIS}

Segundo Torres (2001), podemos identificar três grandes formações sociais e regimes políticos predominantes na América Latina, ainda que marcados pela presença de momentos de autoritarismo estatal na forma de corporativismo, ditaduras militares e de populismos autoritários (TORRES, 2001). Esses três tipos de estado são: o liberal-conservador, o desenvolvimentista e o neoliberal. Ainda que a relação estado/sociedade civil, através do sistema educacional supõem diversas e complexas articulações e penetrações em ambos os sentidos, podemos afirmar que os governos de Argentina e Brasil foram marcados por estas perspectivas de Estado com importantes repercussões na educação.

Os sistemas educacionais de Argentina e Brasil datam do século XIX, ainda que no Brasil tenha se constituído como tal depois de 1930. Nesse sentido, conforme o desenvolvimento apresentado por Torres (2001), podemos localizar o período de conformação dos sistemas educacionais no primeiro tipo, o estado liberal-conservador. Esse estado gestou os modelos educacionais na região entre 1880 e 1930, dependendo das histórias nacionais, uma situação que chegou até o final da segunda guerra mundial, passando pela crise de 1929 que reorientou o eixo geopolítico de América Latina e deu lugar a presença cada vez maior do imperialismo estadunidense.

Se bem que, em ambos os países, houve processos político-institucionais similares desde os anos de 1950 até a atualidade (desenvolvimentismo, ditaduras, democracia), as diferenças estruturais entre eles são de relevância e, no desenvolvimento desigual e combinado da educação latino-americana (PUIGGRÓS, 1988), referem-se principalmente ao campo da produção de conhecimentos (ISOLA, 2013) - aspecto que interessa destacar aqui pela incidência nos processos de cobertura escolar e democratização do sistema educacional e a sua estrutura de governo.

O denominador comum dos governos das primeiras décadas de 2000 na região é a relativamente ampla oposição ao consenso político reformista dos 90 e a recuperação da centralidade do Estado na implementação de políticas mais 
inclusivas (MOREIRA et al., 2008 apud FELDFEBER; GLUZ, 2011); contudo, essas políticas continuam convivendo com velhas modalidades de intervenção estatal que reclama um trabalho integral e diversificado, que não perca de vista a importância do coletivo (PINI; GÓMEZ MELO: 2011).

Tal como afirma Bittar (2012), para o Brasil, o século XX se concluiu sem garantir a escolarização pública, integral, universal e laica para todos as crianças e jovens. O percentual de analfabetos funcionais em 2011, dos 15 aos 64 anos, ainda estava em $68 \%$ e entre eles, existia também 8,59 \% de analfabetos totais, segundo dados do IIPE - UNESCO/OEI com base no PNAD. Essa mesma fonte revela que Argentina, no mesmo ano, tinha 0,99\% de analfabetismo. $\mathrm{Na}$ situação brasileira, aliás, a problemática racial joga um papel importante, já que a discriminação se evidencia em $66 \%$ de pretos e pardos dentro desse total.

Em meio a esse cenário, a questão da democratização das instituições tem no Brasil uma longa data. Seguindo as expressões de Stubrin (2007) pode-se reconhecer que o campo das políticas educacionais no contexto brasileiro, durante as últimas décadas, foi atravessado por intensos enfrentamentos entre o Estado e a sociedade civil representada pelas ações protagonizadas por associações e organizações sociais e populares, sindicatos, fóruns, campanhas e outros movimentos organizados. Ao longo das décadas de 1980 e 1990, o país assistiu uma importante multiplicação e ampliação de movimentos de luta e reivindicação, na disputa pelo reconhecimento da existência de projetos educacionais alternativos. Durante esse período, introduziram-se uma série de modificações na administração dos sistemas de ensino municipais, estaduais e federal que, resultando em uma grande diversidade de experiências no setor, tiveram como marca significativa a participação de atores organizados da sociedade civil.

Desta forma, após a CF de 1988, com a institucionalização do princípio da gestão democrática do ensino público, sua ratificação na LDBEN de 1996 e nos consequentes PNEs, esse princípio foi reproduzido nas constituições estatais e leis orgânicas municipais (PINI; GÓMEZ MELO, 2011). Recentemente, após o PNE 2014-2024 colocar o prazo de 2016 para que os planos estaduais e municipais operacionalizem neles esse princípio, houve novo impulso, muito embora, constatemos que os dispositivos da gestão democrática, como a elaboração participativa dos Projetos Político-Pedagógicos, o funcionamento de Conselhos Escolares e a consulta pública para o provimento do cargo de diretor, ainda não se concretizem generalizadamente no país.

Em contrapartida, na Argentina, a democracia escolar não seguiu os mesmos caminhos. Vior (1999) aponta que os organismos colegiados estiveram presentes nas primeiras leis que regularam a escola primaria. Isto obedeceu, entre outras razões, à valorização que D. F. Sarmiento e a tradição democrática 
liberal fizeram do modelo descentralizado e participativo vigente nos Estados Unidos. Porém, esses colegiados que - dentro de os limites democráticos liberais com que o governo da educação podia organizar-se a meados do século XIX demostraram um avanço democratizador, foram substituídos pelo Ministério de Educação. O que aconteceu é que aqueles germes de condução representativoparticipativas foram sistematicamente agredidos durante o último século pelos governos conservadores, civis ou militares. No entanto, apesar desta constatação e das recentes crises que enfrentou, a Argentina continua sendo um país com indicadores educacionais favoráveis e com um sistema de educação pública com escolarização inicial, primária e secundária obrigatória e gratuita para a população a partir dos 4 anos de idade, em comparação com outros países de América Latina, por mais que na atualidade registre um grande número de jovens fora da escola.

\section{REFERÊNCIAS}

ANSALDI, W. (org.). La democracia en América Latina, un barco a la deriva. Buenos Aires: Fondo de Cultura Económica, 2006.

BITTAR, Marisa; BITTAR, Mariluce. História da educação no Brasil: a escola pública no processo de democratização da sociedade. In: Rev. Acta Scientiarum Education, Maringá, v. 34, n. 02, p. 157-168, jul./dez. 2012.

CALENA, P. Los desarrollistas de la 'dictadura liberal'. La experiencia del Ministerio de Planeamiento durante el Proceso de Reorganización Nacional en la Argentina. In: Rev. Anos 90, Porto Alegre, v. 19, n. 35, p. 169-190, jul. 2012 file:///C:/Users/silvi/Downloads/Los_desarrollistas_de_la_dictadura_libe.pdf

FÁVERO, O. A descentralização dos sistemas de educação básica: crise do planejamento central? In: OLIVEIRA, D.A.; DUARTE, M.T.T. (orgs.) Política e trabalho na escola: administração dos sistemas públicos de educação básica. Belo Horizonte: Autêntica, 1999.

FELDFEBER, M.; GLUZ, N. Las políticas educativas en Argentina: herencias de los '90, contradicciones y tendencias de nuevo signo. In: Rev. Educação e Sociedade, Campinas, v. 32, n. 115, p. 339-356, abr.-jun. 2011. Disponível em http://www.scielo.br/pdf/es/v32n115/v32n115a06.pdf. Acessado em abril de 2019. 
FELDFEBER, M.; GLUZ, N. Las políticas educativas en Argentina: herencias de los ' 90 , contradicciones y tendencias de 'nuevo signo'. In: Educação Social, vol. 32, n. 115. Campinas Apr/June, 2011. Disponível em: http://dx.doi. org/10.1590/S0101-73302011000200006 Acessado em novembro de 2013.

GARCIA, W. E. Planejamento e Educação no Brasil: a busca novos caminhos. In: KUENZER, A. Z.; CALASANZ, M. J. C.; GARCIA, W. Planejamento e Educação no Brasil. São Paulo: Cortez, 2003.

GIARRACA, N.; MONTENEGRO, J. et al. Cuando el territorio es la vida: la experiencia de los Sin tierra en Brasil. Universalismo pequeño. In: Experiencia de investigación 1. Buenos Aires: GEMSAL, 2006.

GÓMEZ MELO, D.; PINI, E. Argentina y Brasil: cambios y contradicciones en las políticas educativas. Anales del IV Congreso Nacional y III Encuentro Internacional de Estudios Comparados en Educación: Buenos Aires, 2011.

HORTA, J.S.B. Plano Nacional de Educação: da Tecnocracia à Participação Democrática. In: CURY, C. R. J. et al. Medo à liberdade e Compromisso Democrático. LDB e Plano Nacional de Educação. São Paulo: Editora do Brasil, 1997.

ISOLA, G. N. (2013). Vecinos distantes: campo académico en educación en Brasil y la Argentina. Anales del XI Congreso Nacional de Investigación Educativa. Ciudad de México. Disponível em: http://www.comie.org.mx/congreso/ memoriaelectronica/v11/docs/area_04/0133.pdf. Acessado em janeiro de 2014.

KRAWCZYK, N. Pesquisa comparada em educação na América Latina: situações e perspectiva. In: Educação Unisinos, vol. 17, no 3. 2013

MACOR, D. Estado, democracia y ciudadanía. Una perspectiva histórica. In: MACOR, D. (org.), Estado, democracia y ciudadanía. Red de Editoriales de Universidades Nacionais y diario Página 12, Editorial La Página, Buenos Aires, 2000.

MOREIRA, C.; RAUS, D.; GOMEZ LEYTON, J.C. (org.). La nueva política en América Latina: rupturas y continuidades. Montevideo: FLACSO; UNLA; UARCIS; TRILCE, 2008. 
NOHLEN, D. Diccionario de Ciencia Política: Teorías, métodos, conceptos, dos tomos, Ciudad de México: Porrúa, 2006.

OLIVEIRA, D. A. D. (2005). A educação no contexto das políticas sociais atuais: entre a focalização e a universalização. In: Linhas Críticas, 11 (20), (2740). Disponível em: http://seer.bce.unb.br/index.php/linhascriticas/article/ view/5370/4475. Acessado em outubro de 2013.

OSZLAK, O. Estado y sociedad: nuevas reglas de juego? In: Revista Reforma y Democracia No 9 de CLAD. Caracas, 1997.

PLOMÉ, A. Reforma del Estado y descentralización educativa. El caso de la provincia de Santa Fe (1992-1995). Universidad Nacional de Rosario: Rosario, 2002.

PUIGGRÓS, A. Qué pasó en la educación argentina. Breve historia de la conquista hasta el presente. Edit. Galerna: Buenos Aires, 2006.

SAVIANI, D. História das ideias pedagógicas do Brasil. Campinas: Autores Associados, 2007.

SOUTHWELL, M. La tensión desigualdad y escuela. Breve recorrido histórico de sus avatares en el Río de la Plata. In: MARTINIS, P.; REDONDO, P. Igualdad y educación: escrituras entre dos orillas. Buenos Aires: Del Estante Editorial, 2006.

STUBRIN, F. (org.). Participación e incidencia de la sociedad civil en las políticas educativas: el caso brasileño. FLAPE, 2007.

TORRES, C. A. Grandezas y miserias de la educación latinoamericana del siglo veinte. CLACSO, 2001. Disponível em: http://bibliotecavirtual.clacso.org. ar/clacso/gt/20101010031230/2torres.pdf. Acessado em janeiro de 2014.

VIOR, S. (org.). Educación y Estado en las Provincias. Buenos Aires: Miño y Dávila Editores, 1999.

ZEMELMAN, H. Algunas reflexiones metodológicas a partir del problema de las investigaciones comparativas. In: Krawczyk, N. América Latina. Estado e reformas numa perspectiva comparada (83-105). Sao Paulo: Cortez editora, 2003. 
SILVINA JULIA FERNÁNDEZ, Bacharel em Ciências da Educação graduada na Universidad Nacional de Entre Ríos, Argentina, com mestrado e doutorado em Educação pela Universidade Federal Fluminense. Professora Adjunta III da Universidade Federal do Rio de Janeiro, membro do Núcleo Docente Estruturante do Curso de Pedagogia, da Comissão de Reforma Curricular do Curso de Pedagogia e sub-coordenadora do Curso de Especialização Saberes e Práticas na Educação Básica (CESPEB) - ênfase: Políticas Públicas e Projetos Socioculturais em Espaços Escolares. Foi chefe do Departamento de Administração Educacional no período 2012-2016. Seus trabalhos focalizam a gestão, o planejamento e a avaliação educacional, com foco na democratização da educação, a cidadania, as políticas públicas e o cotidiano escolar. Atualmente desenvolve pesquisas sobre planejamento e gestão escolar no contexto das atuais políticas de planejamento e avaliação de sistemas educacionais. Integra a equipe do LaPOpE - Laboratório de Pesquisa em Oportunidades Educacionais (http:// www.lapope.fe.ufrj.br/).

E-mail: silvina.ufrj@gmail.com

ORCID: http://orcid.org/0000-0003-1879-5131

IVANA DARIELA BRIGNARDELLO, Bacharel e Licenciada em Ciências da Educação e Mestre em Educação pela Universidade Nacional de Entre Rios. Atualmente desempenha atividades de gestão universitária como Secretária Acadêmica e como professora adjunta em Teorias da Administração e docente auxiliar em Planejamento da Educação II no curso de Ciências da Educação da Faculdade de Ciências da Educação da Universidade Nacional de Entre Rios, Argentina.

E-mail: darielabr@gmail.com

ORCID: http://orcid.org/0000-0003-3103-0934

ANDREA ELISABET HERNAN, Bacharel e Licenciada em Ciências da Educação e Mestre em Educação pela Universidade Nacional de Entre Rios, diplomatura em Ciências Sociais: Gestão Educativa (FLACSO-Argentina). Mestranda em Política e Gestão Educativa (Universidade Nacional de Luján) e em Avaliação de Políticas Públicas (Universidade Nacional de Entre Rios). Professora Adjunta de Práticas Políticas e Sociais do Planejamento da Educação e Auxiliar Docente de Estatística Aplicada à Educação, no curso de Ciências da Educação da Universidade Nacional de Entre Rios. Professora de História Social da Educação e Política Educativa Argentina, no Professorado de Nível Primário e no Professorado de Educação Secundária em Biologia do Instituto Superior do Professorado Nº10, Província de Santa Fe.

E-mail: profandreahernan@gmail.com

ORCID: http://orcid.org/0000-0001-6199-916X

BÁRBARA ISABEL CORREA, Bacharel e Licenciada em Ciências da Educação pela Universidade Nacional de Entre Rios, Argentina. Mestranda em Avaliação de Políticas Educacionais (Universidade Nacional de Entre Rios). Professora Adjunta da cátedra Governo e Gestão das Instituições Educativas, desde 2012, e Docente Auxiliar da cátedra Práticas Políticas de Planejamento da Educação, desde 2003, dos cursos de Bacharelado e Licenciatura em Ciências da Educação 
da Universidade Nacional de Entre Rios. Docente Chefe de Trabalhos Práticos da cátedra Metodologia da Pesquisa do Bacharelado em Psicologia, desde 2005, na Universidade Autônoma de Entre Rios. Técnica Pedagógica na Coordenação de Gestão Educativa do Conselho Geral de Educação de Entre Rios, desde 2017. Assessora Pedagógica y Orientadora y tutora na Escola Secundária desde 2002. Pesquisadora categoria IV, integrante de diversos projetos de pesquisa desde 2003, atualmente co-dirigindo dois.

E-mail: barbaracorrea2002@yahoo.com.ar

ORCID: http://orcid.org/0000-0002-1370-1661

GABRIELA ANDRETICH, Bacharel em Ciências da Educação pela Universidade Nacional de Entre Rios com mestrado em Política e Gestão da Educação pela Universidade Nacional de Luján e Doutora em Ciências Sociais pela Universidade Nacional de Entre Rios. Capacitadora em Planejamento Educativo. A partir de 1994, integrante de pesquisas na UNER; desde 2009, diretora de projetos de pesquisa; Professora Associada Ordinária de Planejamento da Educação e Governo de Sistemas e Instituições Educativas e Conselheira Diretiva na Faculdade de Educação da UNER). Docente do Mestrado em Desenvolvimento Rural e Educação (UNER), Mestrado em Desenvolvimento Territorial (UTN) e no Mestrado em Trabalho Social (UNER). Integrante do Comité Acadêmico do Mestrado em Docência Universitária (UNER). Orientadora de graduação e pós-graduação strito senso. Vice-reitora da Universidade Nacional de Entre Rios. E-mail: andretich.gabriela@gmail.com

ORCID: http://orcid.org/0000-0002-2798-5132 